\title{
The selection of optimal conditions for the process of obtaining humic acid from brown coal
}

\author{
Edyta Janeba-Bartoszewicz ${ }^{1, *}$, Dawid Romek $^{1}$, Jarosław Selech ${ }^{1}$, Jacek Marcinkowski ${ }^{1}$ \\ ${ }^{1}$ Poznan University of Technology, Faculty of Transport Engineering, Institute of Machines and \\ Motor Vehicles
}

\begin{abstract}
The type of plant substance from which brown coal is formed and the conditions in which it forms largely influence its characteristics and properties. On account of a lower degree of coalification and calorific value compared to hard coal and a high content of humic substances, brown coal is becoming a valuable fertiliser component. Humic acids contained in brown coal are also found in the soil's humus substances, and their beneficial sorptive and complexing properties are a factor speaking in favour of their use both in agriculture and in other branches of the economy. The article presents the manner of preparing a sample of brown coal in order to determine the content of humic acid intended in particular for use in making chemical fertilisers and for other applications, particularly in agriculture. The optimum conditions in which the amount of humic acid in the sample is the highest were determined. The influence of the proportions of water, $\mathrm{KOH}$, and brown coal, temperature, and mixing time on the solubility of the sample of brown coal was analysed. The solutions were mixed in mixers built especially for this purpose. The solubility of brown coal in the prepared solutions was controlled UV-ViS spectrophotometrically.
\end{abstract}

\section{Introduction}

The fecundity and fertility of soils in land ecosystems is shaped by biological processes based on the transformation of organic matter, both native and introduced with plant and animal residues. The transformations of plant residues in the soil, the process of their humification, and the properties of the humic substances formed are a result of complex chemical and biochemical processes. During mineralisation, organic matter is decomposed, which leads to the formation of mineral compounds. This is the main process of releasing nutrients available to plants, constituting an important link in the circulation of matter and energy flow $[1,2,3]$. Under anaerobic conditions, it takes on the form of putrefaction, resulting in the formation of products such as: $\mathrm{CO}_{2}, \mathrm{H}_{2} \mathrm{O}$, as well as $\mathrm{CH}_{4}, \mathrm{NH}_{3}, \mathrm{H}_{2} \mathrm{~S}$. Under aerobic conditions, the process takes place as rotting, with the following end products: $\mathrm{CO}_{2}$, $\mathrm{H}_{2} \mathrm{O}$, and ions of $\mathrm{NO}^{3-}, \mathrm{PO}_{4}{ }^{3-}, \mathrm{SO}_{4}{ }^{2-}[4,5,6]$. The basic treatment aimed at improving the

\footnotetext{
* Corresponding author: edyta.janeba-bartoszewicz@put.poznan.pl
} 
content of humus in the soil consists in providing it in the form of organic fertilisers or organic waste substances with specific parameters. This fact was the inspiration to search for additional materials rich in organic substance, more resistant to decomposition, and permanently improving the physico-chemical properties of the soil. One of the unconventional forms of organic matter, which has been of interest to many researchers for a century now, is brown coal. The agricultural value of brown coal is related to its structure, chemical composition, and valuable physical and physico-chemical properties.

The key component of brown coal's organic substance is humic acids. They also contain mineral substances, such as nitrogen, phosphorus, and potassium compounds, they are a source of calcium, magnesium, and most micronutrients. A distinctive feature of the structure of brown coal is that it is highly porous and has a well-developed specific surface. It is responsible for its beneficial sorptive abilities, buffering properties, and high water capacity. Significant natural qualities of this organic material also include its exceptional durability, resistance to microbiological decomposition, and the fact that it is free from pathogens $[7,8,9]$. On account of a lower degree of coalification and calorific value and a high content of humic substances, brown coal is becoming a valuable fertiliser component. Due to a high content of humic acids and the resulting similarity to the soil's humus substances, the use of the earthy (smudge) variety of brown coal is beneficial. An increase in the efficiency of the fertilising effect of brown coal can be achieved through its preliminary chemical modification. Chemical treatment of coal material is carried out in the presence of various extracting solutions. The most frequently used ones, characterised by a high degree of extraction of humic acids, are alkaline solutions. The properties of the humic acids obtained vary depending on the raw material from which they were isolated and on the method used to obtain them $[10,11,12]$. The decisive factor influencing the degree of extraction of humic acids from brown coal and their physico-chemical properties is the selection of the raw material used and the alkaline agent.

\section{The experimental part}

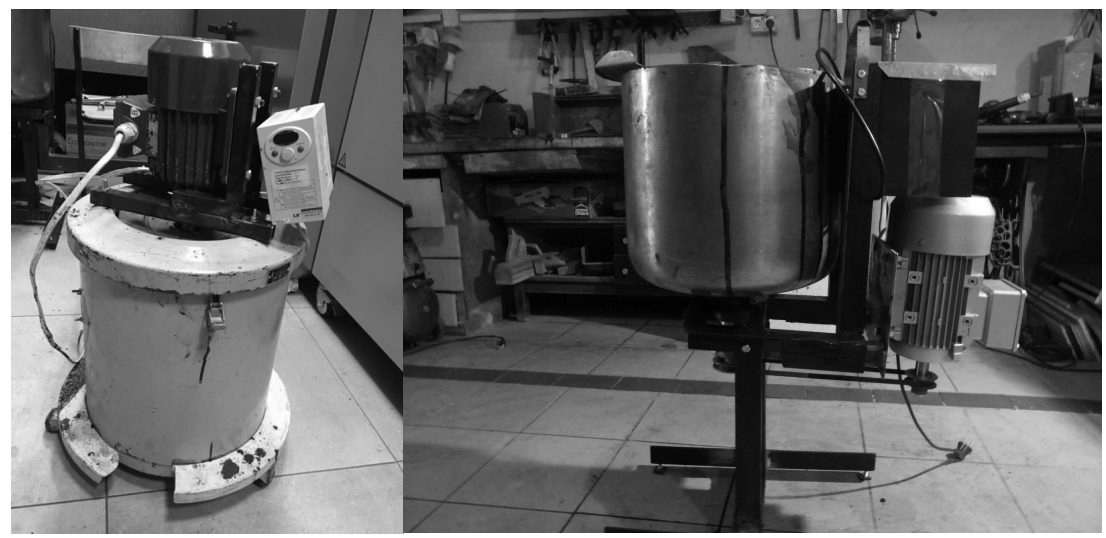

Fig. 1. Mixers.

The aim of the study was to determine the impact of the mixing parameters, such as: revolutions of the mixer arm, temperature, and the proportions of water, $\mathrm{KOH}$, and brown coal on the amount of humic acids obtained. The tests aimed at assessing the properties of the humic acids obtained from brown coal depending on the adopted parameters of the extraction process were performed with the use of analytical techniques and test methods used in the tests of organic material of this type. For this purpose, standard procedures of the UV-VIS spectrophotometric method were used [13]. The moisture content of brown 
coal was $40-50 \%$. An important element of the research was humic extraction. Potassium hydroxide was used as the extractant. The coal was fragmented, mixed with water, hydroxide was added. Optimal coal measurement in accordance with earlier works by Hoffman and colleagues up to $0.5 \mathrm{~mm}[14,15]$. After the specified time, the mixture was separated in the filtration process. The lignite extraction process was carried out in a designed mixer (Fig.1). In grinding process used a high-speed turbine mixer, which was driven by the motor. The speed of the rotor was set by means of a frequency converter.

Absorption spectra $A=f(C)$ are one of the more frequently used methods among spectrophotometric analyses. Monochromatic light passing through the homogeneous solution containing dissolved humus substances is absorbed proportionally to the concentration of the dissolved substance, assuming that the solvent does not absorb light in the given wavelength range. The measurement of beam intensity after passing through the absorbing matter in relation to UV-ViS wavelength results in obtaining the absorption curve. The shape of such curve depends on numerous factors, such as: the structure of the absorbing molecules, solvent type, solution $\mathrm{pH}$, measurement conditions, and the presence of impurities. The type of instrument used to take measurements also plays an important role $[16,17]$. Absorption spectra for brown coal solutions were recorded with the use of the Ultra-3660 UV-ViS double-beam spectrophotometer for measuring the transmission and absorbance of solid, liquid, and gaseous bodies with a high-quality diffraction grating ensuring high measurement accuracy and stability. The apparatus had a test chamber for $10 \mathrm{~mm}$ cuvettes. The spectra included in the article were recorded in the visible range, and the shape and position of the spectrum depending on the conditions in which the sample was prepared (mixing time, temperature, and the proportions of water and $\mathrm{KOH}$ in the sample) was observed. The position of the spectra enabled the determination of the optimum conditions in which the solubility of brown coal is the best and makes it possible to obtain a sufficient amount of humic acids. The samples for spectrophotometric analyses were diluted by a ratio of 1:100 so as to enable the recording of the spectrum in the visible range. In order to test sample stability, spectra for the same samples were measured the next day. The course of the absorption spectrum curves obtained corresponds to a monotonically decreasing line. The decreasing nature of humic acid spectra in the UV-ViS range is related to their structure (the occurrence of aromatic rings and groups of quinone and semiquinone nature in their structure) $[17,18,19]$.

\section{Results and discussion}

Preliminary tests were performed in order to determine the influence of mixing time, the concentration of the $\mathrm{KOH}$ solution, temperature, and the proportions of water to raw material. As a result, the influence of the described factors on the content of humic acids was obtained. For the prepared solutions, spectrophotometric spectra were measured and on their basis, the solubility of brown coal in the sample was determined and the formation of humic acids in an alkaline environment was observed. Table 1 presents parameter values at which the tests were performed. During the experiment, the influence of the individual parameters on the solubility of brown coal in $\mathrm{KOH}$ and the formation of humic acid during the mixing of the sample was analysed. The tests were performed by way of eliminating the influence of the individual parameters on the given spectrum. Table 2 presents all the variable parameters at which the tests were performed. 
Table 1. Parameter values at which solubility of brown coal samples and the formation of humic acid in the solution was observed

\begin{tabular}{|l|c|c|c|c|c|}
\hline Mixing time [min] & 2 & 5 & 20 & 60 & 120 \\
\hline Concentration of the KOH solution [\%] & 0.5 & 1 & 1.5 & 1.7 & 2 \\
\hline Water to coal proportion & $1: 9$ & $1: 4$ & - & - & - \\
\hline Water temperature $\left[{ }^{\circ} \mathrm{C}\right]$ & 27 & 40 & 75 & - & - \\
\hline Revolution $[\mathrm{rpm}]$ & 2,000 & - & - & - & - \\
\hline
\end{tabular}

Table 2. Selected conditions under which the solutions of brown coal in $\mathrm{KOH}$ were analysed with the use of recorded spectrophotometric spectra

\begin{tabular}{|c|c|c|}
\hline $\begin{array}{c}\text { KOH concentration [\%] } \\
\text { and share of coal dry weight }\end{array}$ & Temperature $\left[{ }^{\circ} \mathrm{C}\right]$ & Mixing time [min] \\
\hline $0.5(1: 4)$ & 40 & 2 \\
\hline $0.5(1: 4)$ & 40 & 5 \\
\hline $0.5(1: 4)$ & 40 & 20 \\
\hline $0.5(1: 4)$ & 40 & 5 \\
\hline $1(1: 9)$ & 40 & 5 \\
\hline $1.5(1: 4)$ & 40 & 5 \\
\hline $1.5(1: 4)$ & 27 & 5 \\
\hline $1.5(1: 4)$ & 40 & 5 \\
\hline $1.5(1: 4)$ & 75 & 5 \\
\hline $1.7(1: 4)$ & 40 & 2 \\
\hline $1.7(1: 4)$ & 40 & 5 \\
\hline $1.7(1: 4)$ & 40 & 20 \\
\hline $1.7(1: 4)$ & 40 & 60 \\
\hline $2(1: 4)$ & 40 & 2 \\
\hline $2(1: 4)$ & 40 & 5 \\
\hline $2(1: 9)$ & 40 & 5 \\
\hline $2(1: 4)$ & 40 & 20 \\
\hline $2(1: 4)$ & 40 & 60 \\
\hline & & \\
\hline & & \\
\hline & & \\
\hline
\end{tabular}

The solutions obtained as a result of the tests were used to take samples for spectrophotometric tests, the spectra of which were analysed in terms of the amount of humic acid formed and the solubility of the initial raw material, i.e. brown coal. The solutions were decanted to remove the suspension. A homogeneous solution was obtained which was subjected to spectrophotometric analysis.

In the graphs of absorbance dependence, in the wavelength function, it is clearly visible that time considerably influences the amount of product obtained. Moreover, the temperature and the concentration of $\mathrm{KOH}$ also have an impact. In order to determine the physico-chemical properties of brown coal extracts, absorbance measurements at the wavelength of $664 \mathrm{~nm}, 472 \mathrm{~nm}$, and $280 \mathrm{~nm}$ are usually used. When interpreting the influence of the parameters on the forming products, spectra were analysed in the visible range $(664 \mathrm{~nm})$, as in this range, they absorb substances with a high final degree of humification. Figure 2 presents the influence of temperature on the course and shape of brown coal absorption spectra at the concentrations of $\mathrm{KOH}$ of $1.5 \%$ and raw material of $25 \%$. The test was performed for three different mixing temperatures: $27^{\circ} \mathrm{C}, 40^{\circ} \mathrm{C}$, and $75^{\circ} \mathrm{C}$. Along with the temperature increase, the concentration of the formed product (humic acid) increases as well, which is indicated by the increase in absorbance at the wavelength 
of $640 \mathrm{~nm}$. At the temperature of $75^{\circ} \mathrm{C}$, the graph of absorbance dependence on the wavelength changes shape and the value of absorbance at the wavelength of $640 \mathrm{~nm}$ slightly decreases. This change may be a sign of the formation of additional products of the reaction at the expense of the initial product, i.e. humic acid. The optimum temperature which should be used in further tests should be lower than $75^{\circ} \mathrm{C}$. If the temperature is too high (about $75^{\circ} \mathrm{C}$ ), it causes the product, i.e. humic acid, to decompose, which means that humic acids show little resistance to the effect of excessively high temperatures.

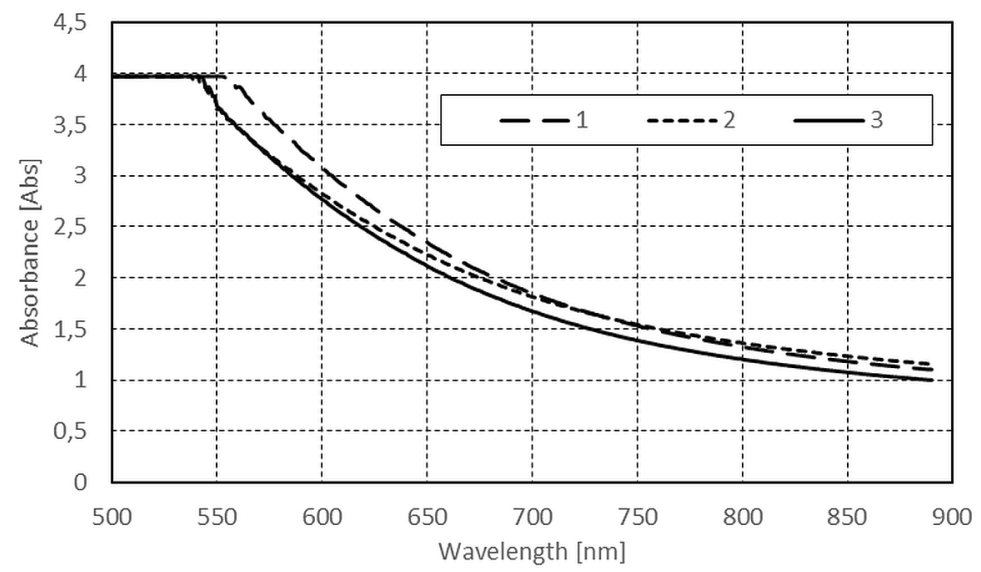

Fig. 2. Absorption spectra for the samples of $25 \%$ solutions of brown coal in $1,5 \% \mathrm{KOH}$ prepared at different temperatures $\left(1\right.$ - temperature $75^{\circ} \mathrm{C}, 2$ - temperature $40^{\circ} \mathrm{C}, 3$ - temperature $27^{\circ} \mathrm{C}$ )

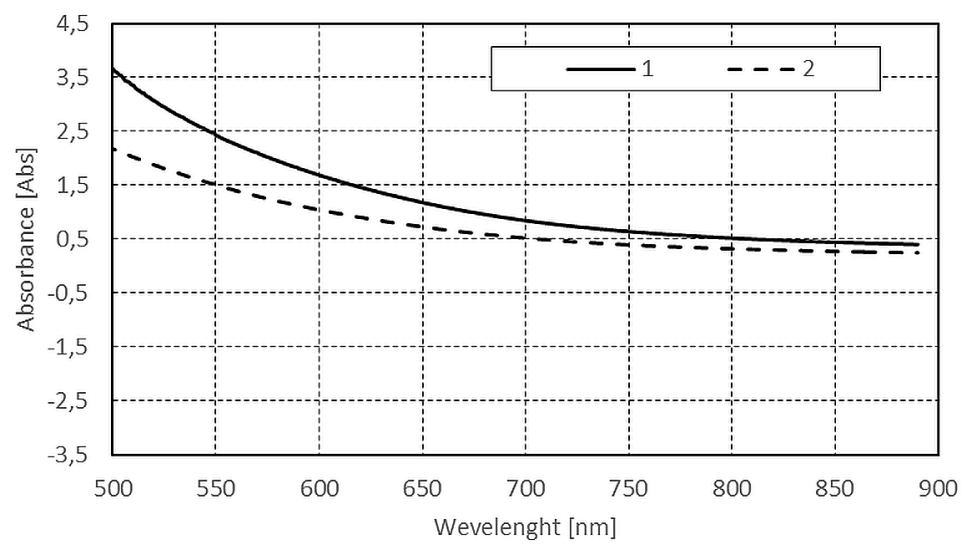

Fig. 3. Absorption spectra for the solutions of brown coal in $\mathrm{KOH}$ with various concentrations of raw materials ( 1 - concentration of brown coal 10\%, 2 - concentration of brown coal $25 \%$ )

Absorption spectra were recorded for solutions with different concentrations of brown coal and $\mathrm{KOH}$ from $1-2 \%$. The curves are shown in Figure 3. For $25 \%$ of coal weight, the concentration of $\mathrm{KOH}$ was $1.5 \%$, whereas for $10 \%$ of raw material weight, it was $2 \%$ (at a temperature of $400 \mathrm{C}$ and mixing time of 5 minutes for all the samples). The shape and position of all the curves is similar, which shows that the optimum concentration of $\mathrm{KOH}$ in the solutions falls within the range of $1.7-2 \%$. Absorbance values typical of the humic acid spectrum at the wavelength of $664 \mathrm{~nm}$ and $472 \mathrm{~nm}$ are very similar, which is why the concentration of coal in $\mathrm{KOH}$ of $2 \%$ was adopted as optimum for further tests. 
The influence of mixing time on the absorption spectrum obtained for two different variants of $\mathrm{KOH}$ concentration, at the same concentration of coal weight, was presented in Figures 4 and 5. Mixing time longer than 20 minutes did not cause a change of position of the recorded absorption spectra, which indicates maximum coal solubility. The amount of product obtained after such mixing time should be the maximum amount. Repeat recording (a day after the first analysis) of absorption spectra for the samples after 20 minutes of mixing results in obtaining the same curves, which indicates stability of the solution and the obtained product of the reaction. In the case of shorter mixing times, repeat recording of the spectra showed a difference in the observed spectra.

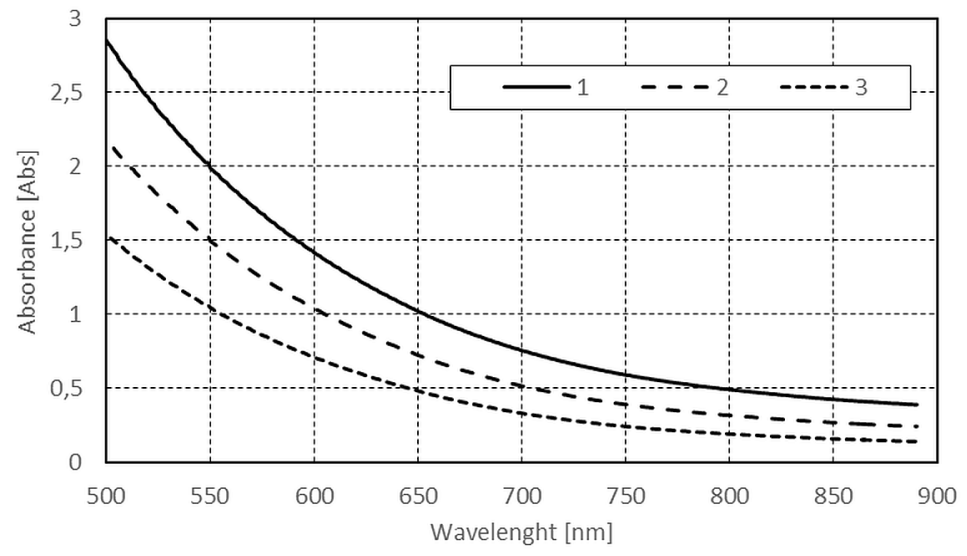

Fig. 4. The influence of mixing time on the course of the absorption curve for a solution of brown coal in $1.7 \% \mathrm{KOH}$, at a temperature of $40^{\circ} \mathrm{C}(1$ - time of mixing sample 5 minutes, 2 - time of mixing sample 10 minutes 3 - time of mixing samples 20 minutes).

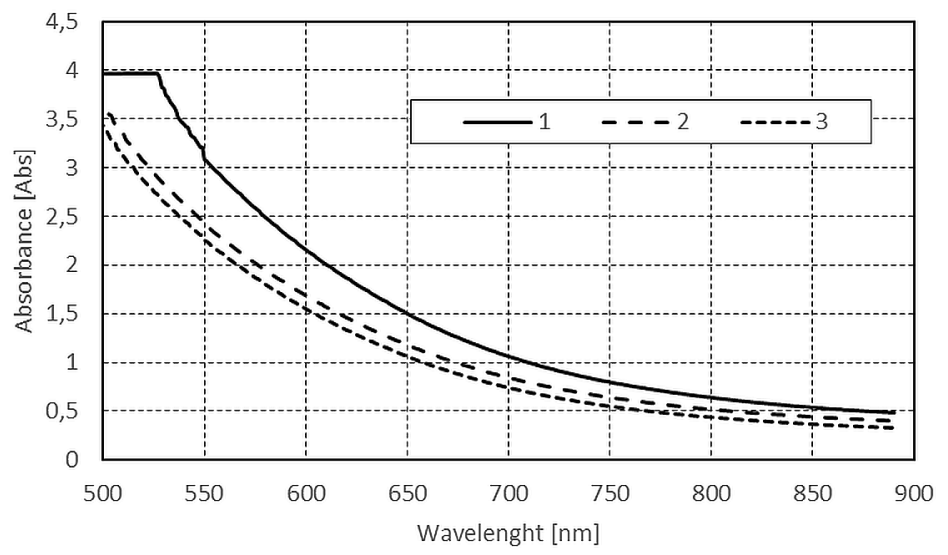

Fig. 5. The influence of mixing time on the course of the absorption curve for a solution of brown coal in $2 \% \mathrm{KOH}$, at a temperature of $40^{\circ} \mathrm{C}$. ( 1 - time of mixing sample 5 minutes, 2 - time of mixing sample 10 minutes 3 - time of mixing samples 20 minutes).

The curves presented in Figures 4 and 5 illustrate the increase in absorbance within the range of 400-600 $\mathrm{nm}$ during mixing time, which characterises the forming humic acids. A quantitative analysis of the forming humic acids will be carried out as part of further studies with the use of a humic acid standard. 


\section{Conclusions}

The tests described in the article made it possible to determine the optimum conditions for preparing brown coal samples in order to identify and obtain humic acid. The optimum concentration of the $\mathrm{KOH}$ solution in which the amount of humic acid is sufficient falls within the range of $1.7-2.0 \%$. Mixing time influences the amount of humic acid in the solution. Extending extraction time causes an increase in the amount of humic acid. The optimum mixing time is 20 minutes. The influence of the temperature of the system on the forming product plays a crucial role. The optimum temperature at which the amount of humic acid is the highest is $40{ }^{\circ} \mathrm{C}$. At this temperature, humic acids retain their properties.

Acknowledgements The paper was prepared within the framework of project POIR.01.01.01-000799/16-00 "Testing the properties and usability of brown coal in order to implement the test results in the production of humic acid"

\section{References}

1. Y. Chen, C.E., H. Magen, J. Soil Sci. Plant Nutr. 50, 1089 (2004)

2. F.H. Frimmel, G. Abbt-Braun, K.G. Heumann, B. Hock, H.D. Luedemann, M. Spiteller, Refractory Organic Substances in the Environment, Wiley-VCH (2002)

3. M.M. Kononova, Soil Organic Matter, Pergamon, Oxford (1996)

4. F.J. Stevenson, Humus chemistry. Genesis, composition, reactions, John Wiley\&Sons, New York (1994)

5. S. Kuwatsuka, K. Tsutsuki, K. Kumada, J. Soil Sci.Plant Nutr. 24, 337 (1978)

6. J.C. Masini, G. Abate, E.C., Lima, L.C. Hahn, M.S. Nakamura, J. Lichtig, H.R. Nagatomy, Anal. Chim. Acta 364, 223 (1998)

7. B. Allard, Geoderma, 130, 77 (2006)

8. A.G. Proidakov, Solid Fuel Chem., 43, 9 (2009)

9. G.D. Chimitdorzhieva, D.B. Andreeva, V.M. Korsunov, Dokl. Biochem. Biophys. 384, 189 (2002)

10. M. Fukushima, S. Tanaka, H. Nakamura, S. Ito, Talanta, 43, 383 (1996)

11. A. Piccolo, Adv. Agron., 75, 57 (2002)

12. T. Adjelkovic, J. Perovic, M. Purenovic, S. Blagojevic, R. Nikolic, D. Adjelkovic, A. Bojic, Mac. J. Chem. Chem. En. 25, 131 (2006)

13. A.P. Black, R.F. Christman, J. Am. Water Works Assoc. 55, 897 (1963)

14. M. Huculak-Mączka, J. Hoffman, K. Hoffman, Chem. Ind. 89, 396 (2010) - (in polish)

15. K. Hoffman, M. Huculak-Mączka, Chem. Ind., 5, 749 (2012) - (in polish)

16. E. Janeba-Bartoszewicz, H. Kozubek, G.L. Hug, W. Urjasz, B. Marciniak, J. Photochem. Photobiol.. A. 140, 133 (2001)

17. E. Janeba-Bartoszewicz, G.L. Hug, E. Andrzejewska, B. Marciniak, J. Photochem. Photobiol.. A, 177, 17 (2006)

18. L.T. Shirshova, E.A. Ghabbour, G. Davies, Geoderma, 133, 204 (2006)

19. O. Francioso, D. Montecchio, P. Gioacchini, C. Ciavatta, L. Cavani, O. Trubetskoj, O. Trubetskaya, Geoderma, 152, 264 (2009) 